\title{
Emergency department visits by patients with venous thromboembolism, 1998-2009
}

\author{
Hussain R. Yusuf, James Tsai, Azfar-E-Alam Siddiqi, Sheree L. Boulet, J. Michael Soucie \\ Division of Blood Disorders, National Center for Birth Defects and Developmental Disabilities, Centers for Disease Control \\ and Prevention, Atlanta, Georgia, USA
}

Correspondence: Hussain R. Yusuf. Address: Division of Blood Disorders, NCBDDD, CDC, 1600 Clifton Rd., MS-E64, Atlanta, Ga 30333, USA. Telephone: 404-498-3937. Fax: 404-498-6799. E-mail: hyusuf@cdc.gov

Received: April 19, 2012

Accepted: May 16, $2012 \quad$ Published: September 1, 2012

DOI : $10.5430 /$ jha.v1n1p1

URL: http://dx.doi.org/10.5430/jha.v1n1p1

\section{Abstract}

Background: Substantial morbidity and mortality may result from venous thromboembolism (VTE), which includes deep vein thrombosis (DVT) and pulmonary embolism (PE). Many VTE cases are diagnosed in outpatient settings, such as emergency departments. The purpose of this study was to estimate and characterize emergency department visits by patients with a primary diagnosis of VTE.

Methods: Data from the National Hospital Ambulatory Medical Care Survey (NHAMCS) for the years 1998-2009 were analyzed. NHAMCS uses a complex multistage design to sample non-federal short-term care hospitals across the United States. Emergency department visits with a primary diagnosis of VTE were identified using ICD-9-CM codes indicating a primary diagnosis of DVT or PE.

Results: Between 2006-2009, an annual average of 201,000 (95\% confidence interval [CI]: 152,000-251,000) emergency department visits were made in the U.S. by patients with a primary diagnosis of VTE as per the criteria used in this study, which was a rate of approximately 67 (95\% CI 50-83) per 100,000 population. The rates during 1998-2001 and 2002-2005 were 31 (95\% CI 21-40) and 46 (95\% CI 35-57), respectively. The rate of visits with a primary diagnosis of VTE was higher among patients $>61$ years of age, when compared to younger patients. Among visits between 1998-2009, selected characteristics that differed between visits by patents with and without a primary diagnosis of VTE included the patient having been discharged from a hospital in the past seven days $(11.7 \%$, vs. $2.1 \%, p<0.01)$.

Conclusion: A substantial number of emergency department visits are made by patients with a primary diagnosis of VTE. Groups with higher likelihood of VTE related visits may include older adults and those recently discharged from a hospital.

\section{Key words}

Deep vein thrombosis, Emergency department, Pulmonary embolism, Venous thromboembolism

\section{Introduction}

Venous thromboembolism (VTE), which consists of deep vein thrombosis (DVT), a blood clot in a deep vein in the body, and pulmonary embolism (PE), the dislodgement of the clot and its passage into the lungs, is an important public health problem. An estimated 300,000-600,000, and perhaps substantially more, cases of VTE occur each year in the U.S. ${ }^{[1,2]}$. 
VTE is associated with substantial morbidity and mortality, with higher fatality rates among patients with PE than DVT ${ }^{[2]}$. One study among patients $>45$ years age found that the 28 -day case fatality rate after the first VTE event among all patients studied was $11 \%$; among patients with cancer related VTE, it was $25 \%{ }^{[3]}$. Approximately $30 \%$ patients with VTE may have recurrent events within 10 years ${ }^{[4]}$. The occurrence of VTE also results in substantial health care costs. The annual direct medical cost associated with a case of VTE ranged from $\$ 7,600$ to $\$ 16,600$, depending on the type of event and diagnosis, according to one study ${ }^{[5]}$.

Although hospitalization is a major risk factor for VTE and nearly half of VTE cases may be associated with hospitalization, i.e. during hospitalization or after discharge, VTEs occur more often in the outpatient setting ${ }^{[6-8]}$. For example, a study assessing characteristics associated with VTE cases among residents in a metropolitan area in Massachusetts found that approximately $74 \%$ of VTE cases occurred in the outpatient setting ${ }^{[6]}$. However, there is comparatively limited knowledge related to the characteristics of outpatient VTE events. Epidemiologic information regarding VTE related outpatient visits may be helpful in improved development and implementation of prevention strategies.

This study assessed emergency department (ED) visits with a primary diagnosis of VTE. The objectives of the study were to assess the number and rate of VTE-related ED visits in the United States, overall and among selected patient groups, during 1998-2009. We also assessed associations between selected visit characteristics and VTE-related ED visits.

\section{Methods}

For this study we used data from the 1998-2009 National Hospital Ambulatory Medical Care Surveys (NHAMCS). This survey uses a complex multistage cluster design to sample hospitals from all 50 states and the District of Columbia and obtains information on ED and outpatient clinic visits. Hospitals included in the survey are those with $>6$ beds, that have average length of patient stay of $<30$ days, and that are not federal or Veterans Administration hospitals. For the ED component, a sample of ED patient visits occurring during a randomly assigned 4-week reporting period is selected from each hospital. For each visit, a primary diagnosis and up to two additional diagnoses are recorded. Also collected are patient's age, sex, race and ethnicity, month of visit, payment type, nursing home residence, ED visit in the past 72 hours, hospital discharge in the past 7 days, metropolitan statistical area (MSA) or non-MSA location of the hospital, and geographic region of the hospital's location. For sex, race, and date of birth, missing data were imputed through random assignment of values based on other available information. Additional information about NHAMCS is available at the Center for Disease Control and Prevention's National Center for Health Statistics website (available at www.cdc.gov/nchs/ahcd/sampham.htm, accessed 7.30.2011).

ED visits by patients who had a diagnosis of DVT or PE were identified using International Classification of Diseases, 9th Revision, Clinical Modification (ICD-9-CM) codes. Visits that had a diagnosis code of 451.1, 451.11, 451.19, 451.81, 451.83, 453.2, 453.4, 453.40, 45341, 453.42, 453.8 (for years 1998-2004), 671.3, 671.30, 671.31, 671.33, 671.4, 671.40, 671.42, and 671.44 in the primary diagnosis field and that did not have an ICD-9-CM code for pulmonary embolism (as indicated below) and that were not indicated to be probable, questionable, or rule out were determined to have a primary diagnosis of DVT-only; those with a diagnosis code of 415.1, 415.11, 415.12, 415.19, 673.2, 673.20, 673.21, 673.22, 673.23, 673.24 (whether or not they also had a ICD-9-CM code for DVT) that were not indicated to be probable, questionable, or rule out were determined to have a primary diagnosis of PE. Visits by patients with either DVT or PE were considered to have a primary diagnosis of VTE.

To increase the sample size, data from several years of the survey were combined for the analysis. The average annual number and $95 \%$ confidence intervals [CIs] of ED visits with a primary diagnosis of VTE overall, and with a primary diagnosis of DVT or PE separately, for the each of the 4-year intervals of 1998-2001, 2002-2005, and 2006-2009 were divided by the averages of the U.S. Bureau of Census' midyear population estimates for these years to derive rates of ED visits per 100,000 population. The average annual number and rates of ED visits with a primary diagnosis of VTE were also estimated by age groups ( 0 - 60 years and $>61$ years), sex, and race (White, Black, and Other). Using the combined data from 1998-2009, the percentage distribution of selected visit characteristics were assessed for ED visits with and without a primary diagnosis of VTE. The following data were collected only in certain years of the NHAMCS survey: visit to the ED 
in the previous 72 hours (2001-2009); residence in a nursing home (2001-2009); and discharge from a hospital in the previous 7 days (2005-2009). Estimates related to these factors were derived by combining data from years in which the information was collected.

SAS, Version 9.2 (SAS Institute, Inc.) was used to conduct analyses using a procedure (proc surveyfreq) that adjusted for the complex survey design in the derivation of variance estimates. The statistical significance of differences in percent distribution of selected characteristics between patients with a VTE diagnosis and patients without a VTE diagnosis were assessed using the Rao-Scott chi-square test, which is a type of Pearson chi-square test modified for use in complex survey designs.

\section{Results}

Table 1. Estimated annual number and rates of emergency department visits by patients with a primary diagnosis of VTE by 4-year periods, NHAMCS, 1998-2009

\begin{tabular}{|c|c|c|c|c|c|c|}
\hline & \multicolumn{2}{|l|}{$1998-2001(n *=143)$} & \multicolumn{2}{|l|}{$2002-2005\left(n^{*}=225\right)$} & \multicolumn{2}{|l|}{$2006-2009\left(n^{*}=278\right)$} \\
\hline & $\begin{array}{l}\text { No. of visits* }(95 \% \\
\text { CI**) }\end{array}$ & $\begin{array}{l}\text { Rate per } \\
100,000 \\
(95 \% \mathrm{CI})\end{array}$ & $\begin{array}{l}\text { No. of visits* }(95 \% \\
\left.\mathrm{CI}^{* *}\right)\end{array}$ & $\begin{array}{l}\text { Rate per } \\
100,000 \\
(95 \% \mathrm{CI})\end{array}$ & $\begin{array}{l}\text { No. of visits* }(95 \% \\
\text { CI**) }\end{array}$ & $\begin{array}{l}\text { Rate per } \\
100,000(95 \% \\
\text { CI) }\end{array}$ \\
\hline $\begin{array}{l}\text { Among all } \\
\left(\mathrm{n}^{*}=488\right)\end{array}$ & $\begin{array}{l}85,000 \\
(60,000-110,000)\end{array}$ & $31(21-40)$ & $\begin{array}{l}133,000 \\
(100,000-165,000)\end{array}$ & $46(35-57)$ & $\begin{array}{l}201,000 \\
(152,000-251,000)\end{array}$ & $67(50-83)$ \\
\hline $\begin{array}{l}\text { Age: } 0-60 \\
\operatorname{yrs}\left(n^{*}=\right. \\
268)\end{array}$ & $\begin{array}{l}39,000 \\
(25,000-54,000)\end{array}$ & $17(10-23)$ & $\begin{array}{l}75,000 \\
(49,000-100,000)\end{array}$ & $30(20-41)$ & $\begin{array}{l}114,000 \\
(83,000-145,000)\end{array}$ & $45(33-58)$ \\
\hline $\begin{array}{l}\geq 61 \text { yrs }\left(n^{*}\right. \\
=220)\end{array}$ & $\begin{array}{l}45,000 \\
(27,000-64,000)\end{array}$ & $\begin{array}{l}106 \\
(62-150)\end{array}$ & $\begin{array}{l}58,000 \\
(42,000-75,000)\end{array}$ & $\begin{array}{l}127 \\
(91-163)\end{array}$ & $\begin{array}{l}87,000 \\
(58,000-116,000)\end{array}$ & $175(117-233)$ \\
\hline $\begin{array}{l}\text { Sex: Men } \\
\left(n^{*}=214\right)\end{array}$ & $\begin{array}{l}33,000 \\
(18,000-48,000)\end{array}$ & $24(13-35)$ & $\begin{array}{l}57,000 \\
(41,000-73,000)\end{array}$ & $40(28-51)$ & $\begin{array}{l}92,000 \\
(65,000-120,000)\end{array}$ & $62(44-81)$ \\
\hline $\begin{array}{l}\text { Women }\left(\mathrm{n}^{*}\right. \\
=274)\end{array}$ & $\begin{array}{l}52,000 \\
(33,000-71,000)\end{array}$ & $37(23-50)$ & $\begin{array}{l}76,000 \\
(51,000-101,000)\end{array}$ & $51(35-68)$ & $\begin{array}{l}109,000 \\
(77,000-141,000)\end{array}$ & $71(50-92)$ \\
\hline $\begin{array}{l}\text { Race: White } \\
\left(n^{*}=401\right)\end{array}$ & $\begin{array}{l}73,000 \\
(49,000-97,000)\end{array}$ & $32(22-43)$ & $\begin{array}{l}114,000 \\
(84,000-143,000)\end{array}$ & $48(36-61)$ & $\begin{array}{l}163,000 \\
(120,000-206,000)\end{array}$ & $68(50-86)$ \\
\hline $\begin{array}{l}\text { Black }\left(\mathrm{n}^{*}=\right. \\
77)\end{array}$ & $\begin{array}{l}11,000 * * * \\
(4,000-18,000)\end{array}$ & $\begin{array}{l}31 * * * \\
(12-49)\end{array}$ & $\begin{array}{l}17,000 * * * \\
(4,000-29,000)\end{array}$ & $\begin{array}{l}45 * * * \\
(12-78)\end{array}$ & $\begin{array}{l}34,000 \\
(18,000-49,000)\end{array}$ & $88(48-128)$ \\
\hline $\begin{array}{l}\text { Other }\left(n^{*}=\right. \\
10)\end{array}$ & $1,000 * * *(0-3,000)$ & $7 * * *(0-18)$ & $3,000 * * *(0-8,000)$ & $\begin{array}{l}15 * * * \\
(0-41)\end{array}$ & $4,000 * * *(0-10,000)$ & $20 * * *(0-45)$ \\
\hline
\end{tabular}

*The unweighted number of observations of visits with diagnosis of VTE.

${ }^{* *} \mathrm{CI}=$ Confidence interval

***Estimates are based on less than 30 observations and/or have relative standard errors of $>30 \%$ and therefore are not reliable

Of a total unweighted number of 393,645 ED visits in the 1998-2009 NHAMCS sample, 488 visits had a primary diagnosis of VTE (319 DVT and $169 \mathrm{PE}$ ) as per the criteria used in this study. The estimated annual number of ED visits by patients with VTE was approximately 85,000 (95\% CI: 60,000-110,000) during 1998-2001, 133,000 (95\% CI: 100,000-165,000) during 2002-2005, and 201,000 (95\% CI: 152,000-251,000) during 2006-2009 (Table 1). The rate of ED visits by patients with a primary diagnosis of VTE per 100,000 population increased from 31 (95\% CI: 21-40) during 1998-2001 to 67 (95\% CI: 50-83) during 2006-2009. Rates of ED visits with a primary diagnosis of VTE among people $\geq 61$ years of age were several times higher than the rates among younger people in each 4-year period (Table 1). Most visits with a primary diagnosis of VTE among people $<61$ years of age occurred among those who were 21-60 years of age; in this latter group, the rates of visits with a primary diagnosis of VTE per 100,000 population during the three consecutive time periods were 24 (95\% CI: 15-34), 47 (95\% CI: 31-63), and 68 (95\% CI: 50-87), respectively (data not shown in the table). The estimated rates of ED visits by patients with a primary diagnosis of VTE per 100,000 population among men and women during 2006-2009 were 62 (95\% CI: 44-81) and 71 (95\% CI: 50-92), respectively (Table 1). 
During this period, the rates of visits among Whites and Blacks were 68 (95\% CI: 50-86) and 88 (95\% CI: 48-128), respectively.

Of ED visits by patients with primary diagnosis of VTE during 2006-2009, approximately 123,000 (95\% CI: 91,000-156,000) had a primary diagnosis of DVT and 78,000 (95\% CI: 53,000-103,000) had a primary diagnosis of PE. The estimated annual rate of ED visits by patients with a primary diagnosis of DVT during 1998-2001 and 2006-2009 were 22 (95\% CI 14-29) and 41 (95\% CI 30-52), respectively (Figure 1). For PE, the rates during the two periods were 9 (95\% CI 5-13) and 26 (95\% CI 17-34), respectively.

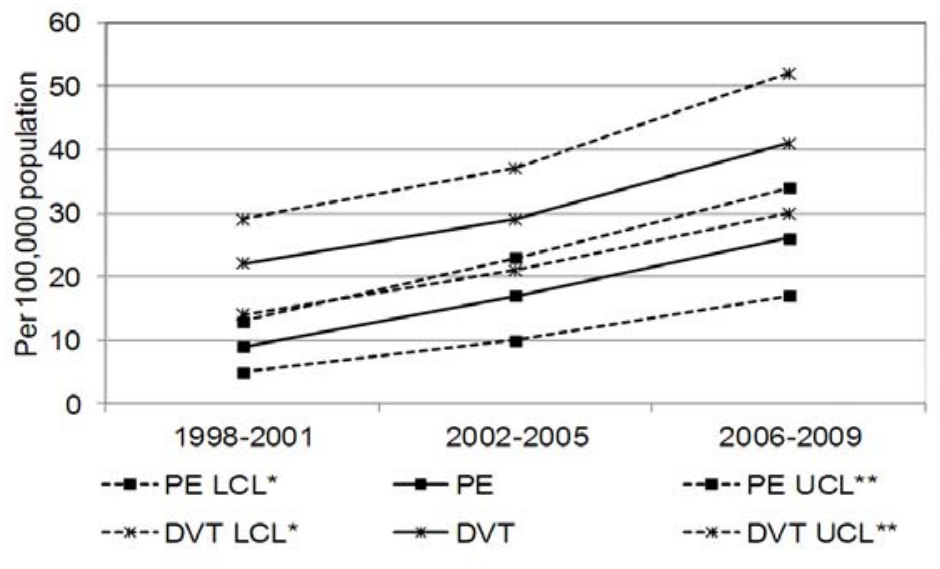

Figure 1. Estimated annual rates ( $95 \%$ CIs) of emergency department visits by patients with a primary diagnosis of DVT or PE per 100,000 population during 1998-2001, 2002-2005, and 2006-2009

The percentage distributions of a number of characteristics differed for ED visits by patients with a primary diagnosis of VTE compared to visits by patients without a primary diagnosis of VTE (Table 2). The differences in percentage distribution were statistically significant for region, source of payment, if the patient resided in a nursing home, and if the patient was discharged from a hospital in the past seven days. Approximately 11.7\% (95\% CI 7.1-16.4) of ED visits with a primary diagnosis of VTE occurred among those who were discharged from a hospital in the past seven days compared with $2.1 \%$ (95\% CI 2.0-2.3) of visits without a primary diagnosis VTE, chisq $p<0.01$.

\section{Discussion}

The findings of this study indicate that a substantial number of ED visits occur each year with a primary diagnosis VTE. Approximately $60 \%$ of the VTE visits had a primary diagnosis of DVT and $40 \%$ had a primary diagnosis of PE in the most recent time period assessed. These findings are consistent with other reports that have looked at outpatient setting diagnosis of VTE, DVT, and/or PE ${ }^{[8,9]}$. These findings also emphasize the need for more public health efforts for prevention and management of VTE.

The rate of ED visits per 100,000 populations by patients with a primary diagnosis of VTE was several times greater for older adults. Age is a major risk factor for VTE and incidence rates are much higher among older adults. For example, a number of studies have reported rates of DVT that were 6 to 13 times higher among older adults compared to younger age groups ${ }^{[10,11,12]}$. Nonetheless, we found that a substantial number of ED visits were made by comparatively younger adults with a primary diagnosis of VTE, e.g. $<60$ years of age. This finding highlights the important fact that VTE affects a broad range of ages. 
The findings of this study also suggest that ED visits by patients with a primary diagnosis of VTE may be increasing. For VTE, as well as for DVT and PE separately, the estimated rates were higher during 2006-2009 compared to 1999-2001 and the corresponding confidence intervals did not overlap; in addition, the point estimates were increasingly higher in more recent time periods. There may be several reasons why the number of ED visits by patients with a primary diagnosis of VTE may be increasing or may not have declined. One reason is that the availability and utilization of comparatively newer diagnostic procedures for diagnosis of VTE have increased in the past several years ${ }^{[13-15]}$ and this has probably resulted in greater recognition of VTE occurrences. For example, a study by Kocher et al. found that between 1996 and 2007 the use of CT scans in emergency departments across the U.S. more than tripled; it increased by more than 5 times respectively among patients presenting with chest pain and patients presenting with shortness of breath ${ }^{[15]}$. There is also more awareness of VTE now compared to before ${ }^{[1,2]}$. The population makeup of the US has changed over the past several years with a higher proportion of the population in older age groups who are at higher risk of VTE. The rates of VTE occurrence possibly could also have been affected by changes in the prevalence of VTE risk factors, such as obesity ${ }^{[16,17]}$.

Table 2. Percentage distribution emergency department visits by patients with and without a primary diagnosis of VTE, by selected characteristics, 1998-2009

\begin{tabular}{|c|c|c|c|}
\hline Characteristic & $\begin{array}{l}\text { VTE visits \% (95\% CI) } \\
1998-2009 \text { Unweighted } n=488\end{array}$ & $\begin{array}{l}\text { Non-VTE visits \% (95\% CI) } \\
1998-2009 \text { Unweighted } n=393,157\end{array}$ & Chisq $p$ \\
\hline \multicolumn{4}{|l|}{ Expected payment source: } \\
\hline Medicare & $40.1(34.2-46.1)$ & $15.3(14.8-15.8)$ & $<0.01$ \\
\hline Medicaid & $10.3(6.5-14.1)$ & $21.4(20.6-22.3)$ & \\
\hline Private insurance & $37.2(31.8-42.5)$ & $36.1(35.2-37.0)$ & \\
\hline Other or Unknown & $12.4(8.6-16.2)$ & $27.1(26.2-28.1)$ & \\
\hline \multicolumn{4}{|l|}{ Region: } \\
\hline Northeast & $21.8(16.0-27.7)$ & $19.0(16.8-21.3)$ & $<0.01$ \\
\hline Midwest & $30.7(23.4-38.0)$ & $23.7(20.3-27.0)$ & \\
\hline South & $28.4(22.0-34.8)$ & $39.3(35.5-43.1)$ & \\
\hline West & $19.1(12.6-25.7)$ & $18.0(15.2-20.8)$ & \\
\hline \multicolumn{4}{|l|}{ Hospital location: } \\
\hline Metropolitan Statistical Area & $84.1(77.1-91.1)$ & $81.8(76.2-87.4)$ & 0.30 \\
\hline Non- Metropolitan Statistical Area & $15.9(8.9-22.9)$ & $18.2(12.6-23.8)$ & \\
\hline \multicolumn{4}{|l|}{ Season when visit occurred: } \\
\hline Winter & $26.7(21.6-31.7)$ & $24.6(23.4-25.7)$ & 0.17 \\
\hline Spring & $26.8(21.8-31.9)$ & $25.5(24.4-26.7)$ & \\
\hline Summer & $27.3(21.9-32.8)$ & $25.2(24.1-26.3)$ & \\
\hline \multirow[t]{2}{*}{ Autumn } & $19.2(14.7-23.7)$ & $24.7(23.5-25.8)$ & \\
\hline & 2001-2009 Unweighted $n=424$ & 2001-2009 Unweighted $n=322,321$ & \\
\hline \multicolumn{4}{|l|}{$\begin{array}{l}\text { Seen in Emergency Room in past } 72 \\
\text { hours: }\end{array}$} \\
\hline Yes & $5.1(2.3-7.9)$ & $3.4(3.2-3.5)$ & 0.14 \\
\hline No or Unknown & $94.9(92.1-97.7)$ & $96.6(96.5-96.8)$ & \\
\hline \multicolumn{4}{|l|}{ Nursing home residence: } \\
\hline Yes & $7.8(4.9-10.6)$ & $2.2(2.0-2.3)$ & $<0.01$ \\
\hline \multirow[t]{2}{*}{ No or Unknown } & $92.2(89.4-95.1)$ & $97.8(97.7-98.0)$ & \\
\hline & 2005-2009 Unweighted $n=267$ & 2005-2009 Unweighted $n=173,753$ & \\
\hline \multicolumn{4}{|c|}{ Discharged from hospital in past 7 days: } \\
\hline Yes & $11.7(7.1-16.4)$ & $2.1(2.0-2.3)$ & $<0.01$ \\
\hline No or Unknown & $88.3(83.6-92.9)$ & $97.9(97.7-98.0)$ & \\
\hline
\end{tabular}

The point estimates of the rates of ED visits with primary diagnosis of VTE were slightly higher among women than men during all three time periods, however, the confidence intervals overlapped. Pregnancy and the post-partum period are important risk factors for VTE ${ }^{[2,7,11,18]}$. Also higher risk of VTE is associated with oral contraceptive use and hormone 
replacement therapy ${ }^{[2,11]}$. VTE risk has been found to be higher in women than men during reproductive years ${ }^{[2]}$. However, research has not consistently indicated a higher incidence in general among women ${ }^{[11]}$. It is not clear why the estimates of rates of ED visits with a primary diagnosis of VTE were slightly higher among women in this study.

Other studies have found higher rates of VTE among African Americans compared to other racial/ethnic groups including whites ${ }^{[19-21]}$. A study conducted using 1996 California hospital discharge data found that the incidences of VTE per 100,000 adults were $103 \pm 2.1$ among whites and $138 \pm 6.5$ among African Americans ${ }^{[20]}$. The findings of this study suggest that rates of ED visits with a primary diagnosis of VTE may also be higher among African Americans, however, confidence limits overlapped. More research is needed related to racial/ethnic disparities in occurrence as well as causes and outcomes of VTE. Available information indicates that the prevalence of a number of hereditary conditions, such as factor V Leiden, that increases the risk of thrombosis, is lower among African Americans ${ }^{[22,23]}$. However, several other risk factors, such as hypertension and diabetes, have been found in higher rates among African-Americans with VTE compared to whites ${ }^{[11,22,23]}$.

Hospitalization is a major risk factor for VTE ${ }^{[2,7]}$. A population based study among Olmsted County residents in Minnesota reported hospitalization to be strongly associated with subsequent VTE. In that study, the odds ratio for hospital or nursing home confinement without recent surgery among patients with a first lifetime occurrence of VTE was 7.98 (95\% confidence interval 4.49-14.18) ${ }^{[24]}$. The present study found that the likelihood of the patient having been discharged from a hospital in the past seven days was greater among visits with a primary diagnosis of VTE than visits without a primary diagnosis of VTE. One reason for the increased risk of VTE associated with hospitalization may be that such patients are comparatively sicker and more likely to have comorbidities that increase the risk for VTE. Additional supplemental analysis of our study data indicated that among patients $>60$ years of age with a hospital discharge in the past seven days, approximately $11.4 \%$ had a diagnosis of heart failure, stroke, or cancer compared to $7.0 \%$ among same age group patients without a hospital discharge in past seven days (data not shown). In addition, among visits with a primary diagnosis of VTE, the patient was more likely to have been residing in a nursing home compared to visits without a primary diagnosis of VTE. It is possible that this latter finding is explained by the fact that VTE rates are higher among older adults and that nursing home residents are commonly older adults. Our study lacked sufficient sample size to appropriately assess associations between VTE and nursing home residence, stratified by age group. It is unclear why percent distributions of visits with and without a primary diagnosis of VTE varied by region.

\section{Limitation}

An important limitation of this study is that it is likely that a proportion of the ED visits categorized in this study to have a primary diagnosis of VTE were not VTE because of misclassification and other reasons. For example, the ICD-9-CM code 453.8 used to categorize patients as having a DVT diagnosis among visits during 1998-2004 may not have been highly specific and may have included cases that were not DVT. More specific ICD-9-CM codes were added in October of 2004, and in this study we included those instead to identify DVT for years 2005-2009. Thus the ICD-9-CM coding used varied to an extent between time period assessed; however, since the less specific code was used for the earlier time periods (1998-2001 and 2002-2005), bias related to this would probably have affected the temporal increases in visits with a primary diagnosis of VTE towards the null. We did not have information on imaging test confirmation of VTE cases. It is also likely that we missed identifying a proportion of ED visits for VTE; for example, a number of visits with ICD-9-CM codes for unspecified venous thrombosis that were not counted in this study may have been VTE visits. The findings of this study should be interpreted in these contexts. As there were a limited number of observations, the estimates of the number of visits by patients with a primary diagnosis of VTE and percent distributions of selected characteristics had relatively wide confidence ranges limiting the ability to assess statistical significance of differences by selected characteristics. 


\section{Conclusion}

Substantial numbers of ED visits are made by patients with a primary diagnosis of VTE with the rates being much higher for older adults. The rate of ED visits by patients with a primary diagnosis of VTE may be increasing. The findings of this study add to the epidemiologic information and improve the knowledge and understanding of VTE occurrence. Such information is needed to increase the awareness of VTE thereby helping to improve management. For example, an increased awareness among ED providers could lead to an improved alertness towards early diagnosis and treatment of VTE cases as applicable. It can also help to improve public awareness and garner support for VTE prevention. This study's findings strengthen the evidence that strategies that address VTE occurrences related to hospitalized patients, to the post-hospital discharge period, and possibly to people in nursing homes may be effective in reaching patient groups at higher risk. The findings of this study also indicate the need for additional research, including research to better understand possible differences in rates of ED visits for VTE by gender and race/ethnicity. There is increasing focus on reducing morbidity and mortality associated with VTE, and more efforts are necessary in this regard.

\section{Conflict of interests}

The authors declare that they have no competing interests.

\section{References}

[1] Raskob GE, Silverstein R, Bratzler DW, Heit JA, White RH. Surveillance for Deep Vein Thrombosis and Pulmonary Embolism: Recommendations from a National Workshop. Am J Prev Med. 2010; 38(4S): S502-S509. PMid:20331950 http://dx.doi.org/10.1016/j.amepre.2010.01.010

[2] Beckman MG, Hooper C, Critchley SE, Ortel TL. Venous Thromboembolism: A Public Health Concern. Am J Prev Med. 2010; 38(4S): S495-S501. PMid:20331949 http://dx.doi.org/10.1016/j.amepre.2009.12.017

[3] Cushman M, Tsai AW, WhiteRH, G, et al. Deep Vein Thrombosis and Pulmonary Embolism in Two Cohorts: The Longitudinal Investigation of Thromboembolism Etiology. Am J Med. 2004; 117: 19-25. PMid:15210384 http://dx.doi.org/10.1016/j.amjmed.2004.01.018

[4] Heit JA, Mohr DN, Silverstein MD, Petterson TM, O'Fallon WM, Melton LJ. Predictors of recurrence after deep vein thrombosis and pulmonary embolism, a population-based cohort study. Arch Intern Med. 2000; 160: 761-768. PMid:10737280 http://dx.doi.org/10.1001/archinte.160.6.809

[5] Spyropoulos AC, Lin J. Direct medical costs of venous thromboembolism and subsequent hospital readmission rates: an administrative claims analysis from 30 managed care organizations. J Manag Care Pharm. 2007; 13(6): 475-86. PMid:17672809

[6] Spencer FA, Lessard D, Emery C, Reed G, Goldberg RJ. Venous Thromboembolism in the Outpatient Setting. Arch Intern Med. 2007; 167(14): 1471-1475. PMid:17646600 http://dx.doi.org/10.1001/archinte.167.14.1471

[7] Heit JA. Venous thromboembolism: disease burden, outcomes and risk factors. J Thromb Haemost. 2005; 3: 1611-17. PMid:16102026 http://dx.doi.org/10.1111/j.1538-7836.2005.01415.x

[8] Barnes GD, Gafoor S, Wakefield T, Upchurch GR, Henke P, Froehlickh JB. National trends in venous disease. J Vasc Surg. 2010; 51: 1467-1473. PMid:20304580 http://dx.doi.org/10.1016/j.jvs.2009.12.070

[9] Maestre A, Sanchez R, Rosa V, et al. Clinical characteristics and outcomes of inpatients versus outpatients with venous thromboembolism: Findings from the RIETE registry. Eur J Intern Med. 2010; 21(5): 377-82. PMid:20816588 http://dx.doi.org/10.1016/j.ejim.2010.07.004

[10] Silverstein MD, Heit JA, Mohr DN, Pettersen TM, O’Fallon WM, Melton III LJ. Trends in the Incidence of Deep Vein Thrombosis and Pulmonary Embolism: A 25-Year Population-Based Study. Arch Intern Med. Arch Intern Med. 1998; 158: 585-593. PMid:9521222 http://dx.doi.org/10.1001/archinte.158.6.585

[11] Stein PD, Matta F. Epidemiology and incidence: the scope of the problem and risk factors for development of venous thromboembolism. Clin Chest Med. 2010; 31: 611-628. PMid:21047571 http://dx.doi.org/10.1016/j.ccm.2010.07.001

[12] Castelli R, Bergamaschini L, Sailis P, Pantaleo G, Porro F. The Impact of an Aging Population on the Diagnosis of Pulmonary Embolism: Comparison of Young and Elderly Patients. Clin Appl Thromb Hemost. 2009 Feb; 15(1): 65-72. PMid:18160565 http://dx.doi.org/10.1177/1076029607308860 
[13] Jones AE, Kline JA. Availability of technology to evaluate for pulmonary embolism in academic emergency departments in the United States. J Thromb Haemost. 2002; 1: 2240-2242. PMid:14521611 http://dx.doi.org/10.1046/j.1538-7836.2003.00370.x

[14] Weir ID, Drescher F, Cousin D, et al. Trends in use and yield of chest computed tomography with angiography for diagnosis of pulmonary embolism in a Connecticut hospital emergency department. Conn Med. 2010; 74: 5-9. PMid:20175366

[15] Kocher KE, Meurer WJ, Fazel R, Scott PA, Krumholz HM, Nallamothu BK. National trends in the use of computed tomography in the emergency department. Ann Emerg Med. 2011; 58: 452-462. PMid:21835499 http://dx.doi.org/10.1016/j.annemergmed.2011.05.020

[16] Flegal KM, Carroll MD, Ogden CL, Curtin LR. Prevalence and trends in obesity among U.S. adults, 1999-2008. JAMA. 2010; 303: 235-241. PMid:20071471 http://dx.doi.org/10.1001/jama.2009.2014

[17] Ageno W, Becattini C, Brighton T, Selby R, Kamphuisen PW. Cardiovascular risk factors and venous thromboembolism: a meta-analysis. Circulation. 2008; 117: 93-102. PMid:18086925 http://dx.doi.org/10.1161/CIRCULATIONAHA.107.709204

[18] Tormene D, Ferri V, Carraro S, Simioni P. Gender and the risk of venous thromboembolism. Semin Thromb Hemost. 2011; 37(3): 193-8. PMid:21455853 http://dx.doi.org/10.1055/s-0031-1273083

[19] Deitelzweig SB, Lin J, Johnson BH, Schulman KH. Venous thromboembolism in the US: does race matter? J Thromb Thrombolysis. 2011; 31: 133-138. PMid:20658176 http://dx.doi.org/10.1007/s11239-010-0503-3

[20] White RH, Zhou H, Murin S, Harvey D. Effect of ethnicity and gender on the incidence of venous thromboembolism in a diverse population in California in 1996. Thromb Haemost. 2005; 93(2): 298-305 PMid:15711746

[21] Zakai NA, McClure LA. Racial Differences in Venous Thromboembolism. J Thromb Haemost. 2011; 9: $1877-1882$. PMid:21797965 http://dx.doi.org/10.1111/j.1538-7836.2011.04443.x

[22] Heit JA, Beckman MG, Bockenstedt PL, et al. Comparison of characteristics from White- and Black-Americans with venous thromboembolism: A cross-sectional study. Am J Hematol. 2010; 85: 467-471. PMid:20575037 http://dx.doi.org/10.1002/ajh.21735

[23] Dowling NF, Austin H, Dilley A, Whitsett C, Evatt BL, Hooper WC. The epidemiology of venous thromboembolism in Caucasians and African-Americans: the GATE Study. J Thromb Haemost. 2003 Jan; 1(1): 80-7. PMid:12871543 http://dx.doi.org/10.1046/j.1538-7836.2003.00031.x

[24] Heit JA, Silverstein MD, Mohr DN, et al. Risk Factors for Deep Vein Thrombosis and Pulmonary Embolism: A Population-Based Case-Control Study. Arch Intern Med. 2000; 160: 809-815. PMid:10737280 http://dx.doi.org/10.1001/archinte.160.6.809 